\title{
Video tracking in the extreme: A new possibility for tracking nocturnal underwater transparent animals with fluorescent elastomer tags
}

\author{
Johann Delcourt • Marc Ylieff • Valérie Bolliet • \\ Pascal Poncin • Agnès Bardonnet
}

Published online: 17 March 2011

(C) Psychonomic Society, Inc. 2011

\begin{abstract}
Initially developed so that an individual could be recognized in mark-recapture studies of aquatic animals, fluorescent visible implant elastomer (VIE) tags are used here for a new application in ethometry: the study of the behavior of transparent animals in dim light or in darkness using automatic tracking technology. The application and validation of this multitracking method is tested in the context of research on the estuarine migratory behavior of the glass eel (Anguilla anguilla), a crucial point to better understand the dynamics of this endangered species. The method makes it possible to measure the activity (notably the distance and speed) of four individuals as a function of tidal and nycthemeral rhythms in the same flume (a circular aquarium simulating river or estuarine conditions) across a wide time scale (from seconds to weeks).
\end{abstract}

Keywords Multitracking $\cdot$ VIE tags $\cdot$ Fish $\cdot$ Anguilla anguilla glass eels · Migration · Swimming behavior . Motion analysis

J. Delcourt $(\triangle) \cdot$ M. Ylieff $\cdot$ P. Poncin

Laboratory of Fish and Amphibian Ethology, Behavioural

Biology Unit, Department of Environmental Sciences and

Management, University of Liège,

22 Quai van Beneden,

4020 Liège, Belgium

e-mail: Johann.Delcourt@ulg.ac.be

V. Bolliet $\cdot$ A. Bardonnet

INRA, UMR Ecobiop, INRA/UPPA,

Pôle d'hydrobiologie de l'INRA,

64310 St pée sur Nivelle, France

V. Bolliet $\cdot A$. Bardonnet

UPPA, UMR Ecobiop, INRA/UPPA,

UFR Sciences \& Techniques Côte Basque,

Allée du parc Montaury,

64600 Anglet, France
Interest in eels has been stimulated in recent decades by declines in recruitment in temperate species: the European Anguilla anguilla L., American A. rostrata Lesueur, and Japanese A. japonica Temminck \& Schlegel (Aida, Tsukamoto, \& Yamauchi, 2003; Aoyama, 2009; Tesch, 2003). The European eel reproduces in the Sargasso Sea (Ginneken \& Maes, 2005; McCleave et al., 1998; Schmidt, 1922), and after hatching, leptocephalus larvae use ocean currents (mainly the Gulf Stream) to migrate to the east Atlantic coasts of the northern hemisphere. They metamorphose into glass eels, probably as they reach the continental shelf. Then glass eels enter estuaries to grow and eventually colonize the freshwater network. The activity during the estuarine migration depends mainly on the tidal cycle, even if lunar and circadian rhythms and/or direct influence of light and tidal coefficient may also interact (Bolliet \& Labonne, 2008; Bureau du Colombier, Bolliet, \& Bardonnet, 2009). Different migratory tactics are suspected on the basis of laboratory experiments: Some individuals subjected to water reversal every $6.2 \mathrm{~h}$ swim only with the current, others only against the current, and some alternate swimming with and against the current at each water current reversal (Bolliet \& Labonne, 2008; Bolliet, Lambert, Rives, \& Bardonnet, 2007). Other glass eels can also remain under shelters and present a low degree of activity. Their propensity to migrate and glass eels' energy content appear to be related and may result in different migratory patterns, possibly leading to estuarine settlement (Bureau du Colombier et al., 2009; Bureau du Colombier, Bolliet, Lambert, \& Bardonnet, 2007).

Unfortunately, little is known about glass eel swimming behavior. Recently, Wuenschel and Able (2008) obtained interesting results in Anguilla rostrata glass eels, based on the critical swimming speed measurement $\left(U_{\text {crit }}\right){ }^{1}$ Their

\footnotetext{
${ }^{1}$ The critical swimming speed measurement $\left(U_{\text {crit }}\right)$ is the maximum water current velocity at which a fish can maintain position.
} 
proposed $U_{\text {crit }}$ value $\left(10-13 \mathrm{~cm} \mathrm{~s}^{-1}\right)$ was much lower than the value proposed by McCleave (1980) for Anguilla anguilla $\left(30 \mathrm{~cm} \mathrm{~s}^{-1}\right)$. Nonetheless, for $U_{\text {crit }}$ estimation, the speeds were not the spontaneous speeds naturally adopted by glass eel. Data based on captures from the wild (Beaulaton \& Castelnaud, 2005) gave an estimated speed of 3-4 km day ${ }^{-1}$, which relates to the progression in the estuary according to circatidal rhythmic activity, but not to swimming speed. Characterizing the migratory swimming behavior of glass eels would provide a better understanding of migration and of its relation to energy status.

Although video tracking to measure aquatic vertebrates' behaviors is frequently used in pharmacology, in toxicology, and in behavioral ontogeny, it remains quite rare in ecological studies (i.e., Denoel et al., 2010; Peake, Matos, \& McGregor, 2006). Moreover, tracking a transparent animal with a water current in the dark is a challenge. Patullo, Jolley-Rogers, and Macmillan (2007), who described how to track crayfish in the night using infrared (IR) light, underlined the extreme difficulty of measuring the movement of an underwater animal, notably the problem of reflection on the water surface. Another limitation of available automatic videotracking systems that work in the dark is that they are not adapted to follow several animals in the same arena.

Visible implant elastomer (VIE) tags (Northwest Marine Technology Inc., Shaw Island, WA, USA) were developed to tag aquatic animals, in the context of mark-recapture protocols in the laboratory and in the field (e.g., Astorga et al., 2005; Brennan, Leber, \& Blackburn, 2007; Jerry, Stewart, Purvis, \& Piper, 2001; Linnane \& Mercer, 1998; Purcell, Blockmans, \& Nash, 2006). A VIE tag consists of an elastomer material with a large panel of color possibilities in the visible spectrum; it is stable in time and is injected in a transparent body area to allow for external individual identification. Tag visibility depends on pigments of the skin and the depth of the injection (personal observation; Imbert, Beaulaton, Rigaud, \& Elie, 2007). Some VIE colors are fluorescent to ultraviolet (UV) light (Bonneau, Thurow, \& Scarnecchia, 1995; Buckley, West, \& Doty, 1994; Frederic, 1997; Uglem, Noess, Farestveit, \& Jorstad, 1996; Wood, \& Martin-Smith, 2004), and such colors were used here.

According to several studies on a large spectrum of fish, crustacean, reptilian, and amphibian species, VIE tags have no effect on mortality and growth (e.g., Buchan, Sun, \& Wagner, 2005; Catalano, Chipps, Bouchard, \& Wahl, 2001; Claverie \& Smith, 2007; Davis, Young-Williams, Hines, \& Zmora, 2004; Imbert et al., 2007; Malone, Forrester, \& Steele, 1999; Regester \& Woosley, 2005). According to Imbert et al., VIE tags do not affect the displacement behavior of tagged glass eels. In addition, their patterns of swimming activity under water current reversal were not affected by VIE tagging (Bolliet \& Labonne, 2008).
Here we used fluorescent VIE tags to automatically detect animals with a video-tracking system used in ethometry: EthoVision Color-Pro (Version 3.1; Noldus, Spink, \& Tegelenbosch, 2001). Numerous commercial video-tracking software systems (i.e., Noldus EthoVision; ANY-maze, Med Associates Inc., St. Albans, VT; Viewpoint; Swistrack) are able to study animal behaviors in a reliable and consistent way over time periods longer than are possible with manual recording methods. These systems can be used to obtain spatiotemporal data such as automatic recording of animal activity, movement, and interaction. It is possible to study the spatial occupation in different zones of the arenas and to obtain spatial measurements such as distance, speed, turning, and so forth. With color-based video tracking, it is possible to simultaneously track several individuals in the same arena.

Theoretically, this system can track 16 moving targets simultaneously in the same arena, on the basis of color detection (Noldus et al., 2001). Each tracked target is detected among a range of the visible spectrum and on the basis of color saturation (explained in detail in Noldus et al., 2001). However, tracking such a large number of colors is impossible in a running water environment, mainly because brightness conditions have to be strictly homogeneous throughout the arena. In still water, Ylieff and colleagues succeeded in tracking only two damselfishes (Chromis chromis) or three sparid fishes Sarpa salpa (Jadot, Donnay, Ylieff, \& Poncin, 2005; Ylieff \& Poncin, 2003; Ylieff, Sanchez-Colero, Poncin, Voss, \& Ruwet, 2000) with color tags, and three goldfishes (Carassius auratus) by their natural skin colors (yellow, red, and white; Ylieff \& Poncin, 2003). In comparison with these studies, we faced two additional difficulties: running instead of still water, and night sampling. Fluorescent VIE tagging was used to meet this challenge.

\section{Materials and methods}

\section{Glass eels and VIE tags}

VIE is available in six fluorescent colors, labeled as red, orange, green, yellow, pink, and blue, that emit light under fluorescence that appears to the human observer as red, yellow, green, green, red, or blue, respectively. The red and pink colors are difficult to discriminate when fluoresced, as are green and yellow. Consequently, only four modalities of fluorescent VIE tags were tested here. To be efficient, tags should be readable and should be retained for the duration of the study. When correctly applied, no tag loss was observed over a period of several months in laboratory experiments in glass eels (Bolliet \& Labonne, 2008; Imbert et al., 2007). 
Glass eels were freshly captured in an estuary of Biscay Bay (France) during the migratory period. Before tagging, eels were anesthetized with an alcoholic solution of eugenol $(10 \%)$. The tagging procedure consisted of a subcutaneous injection of one color elastomer (about $0.01 \mathrm{ml}$ ) just in front of the dorsal fin to create a single color spot (Fig. 1). The position and size of the tag were chosen to allow detection in both front and top views, whatever the swimming orientation of the fish.

\section{Experiments}

After $24 \mathrm{~h}$, the 4 tagged eels were placed in an annular flume (length $=1.50 \mathrm{~m}$, width $=0.5 \mathrm{~m}$, depth $=0.5 \mathrm{~m}$, water depth $=0.25 \mathrm{~m}$; Fig. 2) for 8 days in the presence of 50 other untagged individuals (to maintain a density high enough to observe the typical tidal rhythmic activity of swimming behaviors; Bolliet \& Labonne, 2008). A thin layer $(5 \mathrm{~cm})$ of fine natural yellow sand covered the bottom of the tank. Gravel was not used because it induces substantial background noise under dim light conditions. The water temperature was kept at $11.5 \pm 0.5{ }^{\circ} \mathrm{C}$. The water was continuously filtered through a canister filter filled with activated carbon media. Dim daylight is frequently experienced by estuarine fishes because of water turbidity under natural conditions (Bardonnet, Bolliet, \& Belon 2005). The daylight intensity was $2 \times 10^{-6} \mu \mathrm{W} \mathrm{cm} ~^{-2}$, and light intensity was close to zero at night $\left(7 \times 10^{-9} \mu \mathrm{W} \mathrm{cm}{ }^{-2}\right)$, without $\mathrm{UV}$ lighting. With the UV tube lamp (Philips TL-D, $18 \mathrm{~W}, \mathrm{BLB}$ ),

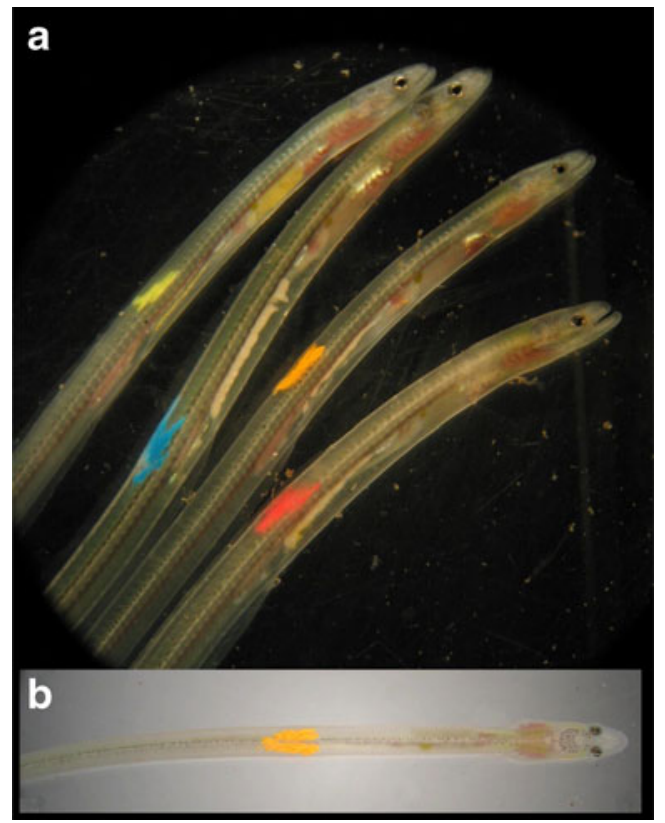

Fig. 1 (A) Lateral view of four eels marked with fluorescent VIE tags; each individual has a different color. (B) View from the top of one marked individual showing the position of the tag on the glass eel body

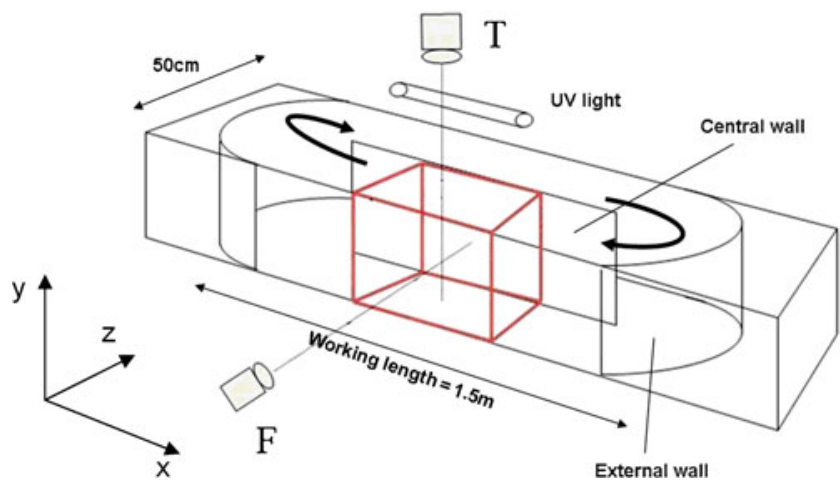

Fig. 2 Schematic view of the annular flume used in this experiment. Two cameras ( $\mathrm{T}$ and $\mathrm{F}$ ) filmed the parallelepipedic red volume (length $=50 \mathrm{~cm}$, width $=22.7 \mathrm{~cm}$, depth $=25 \mathrm{~cm}$ ) to establish the tridimensional position of tagged eels. The central wall was opaque. The water current is represented by bold arrows during one tidal regime $(6.2 \mathrm{~h})$. The water current goes in the opposite direction during the other tidal regime $(6.2 \mathrm{~h})$

day and night lighting did not differ in the UV range and reached $1 \times 10^{-2} \mu \mathrm{W} \mathrm{cm}{ }^{-2}$, but according to both Cottrill et al. (2009) and Hunt, Dulai, Partridge, Cottrill, and Bowmaker (2001), the cone opsins of glass eels and the rod opsins of fish are not sensitive to UV light. The photoperiod

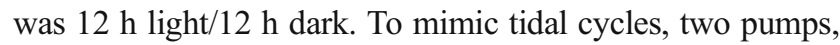
located at opposite ends of the flume, were programmed to work alternatively every $6.2 \mathrm{~h}$ (see Bolliet et al., 2007, for greater detail), in phase with tidal conditions at the capture location. Water current velocities in the arena were measured with a Flo-Mate flow meter (Marsh-McBirney, Inc.). These measures were used to determine nine volumes (bottom, middle, and surface in the vertical plane, and window, middle, and wall [central side] in the horizontal plane), defined in Fig. 3. Water velocity was lower close to the bottom, and it was particularly slow in the central and wall volumes. At the surface and in the middle, water velocity was higher, and it was particularly rapid close in the window side, which defined these nine volumes (in Fig. 3). $\mathrm{V}_{\mathrm{v}}$ corresponded to the water velocity for a volume v. Since water current direction changed at each tide, there were 18 values of $\mathrm{V}_{\mathrm{v}}$.

Two cameras recorded the same arena, one from the front and the other from the top (see Fig. 2). The arena was a parallelepiped volume (length $=50 \mathrm{~cm}$, width $=22.7 \mathrm{~cm}$, depth $=25 \mathrm{~cm}$ ) that represented in volume a spatial sample of one-seventh of the flume, located in an area where turbulence was reduced (Fig. 2). The cameras (CR Sony HD XCD-SX910/CR, CDD 1/2 in., 1,450,000 pixels) automatically adapted their level of sensitivity as a function of the brightness conditions. The camera resolution was $1,280 \times 960$ pixels, and the frame rate was $7.5 \mathrm{fps}$. The image sequences (2-min samples every 15 min for 8 days) were recorded on SATA disks to be analyzed using EthoVision. 


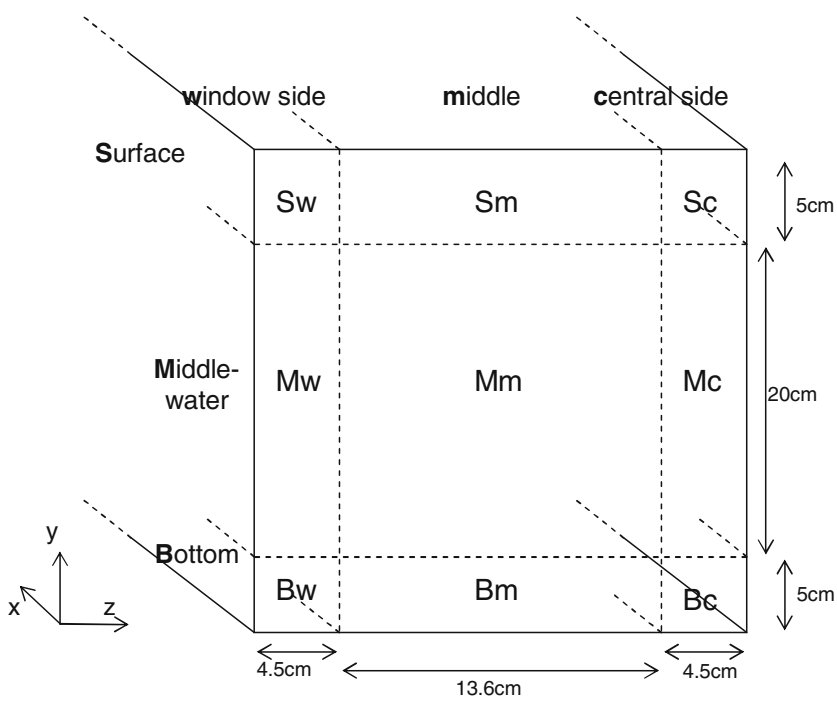

Fig. 3 Definition of the nine volumes characterized by a specific water current velocity for each tide. The tridimensional location of the fish head in a given volume allows for calculating its relative speed, $\mathrm{Sr}$, based on its swimming speed and on the water velocity of the associated volume

The EthoVision measurement of displacement was based on the signal from the front camera, so the movement analysis is in 2-D. The second camera was used to locate fish in a given volume of water current velocity, which was necessary to calculate the relative speed $\mathrm{Sr}$, a parameter reflecting the eels' energy expenditure. The $x, y$ position corresponded to the gravity center (or mass center) was defined as in Noldus et al. (2001):

$x=\frac{1}{A} \sum_{i=1}^{A} x_{i} \quad y=\frac{1}{A} \sum_{i=1}^{A} y_{i}$

$x$ and $y=$ coordinates of the center of gravity; $x_{i}, y_{i}=$ coordinates of pixels $i$ of the tracked object; $\mathrm{A}=$ surface area of the tracked object (in pixels).

When the detected spot was partially outside the camera's visual field, the measured position was not correct, which induced an underestimation of an eel's displacement (Fig. 4). Data on this area (external lateral zone width $=1 \mathrm{~cm}$ ) were excluded from the analysis.

Swimming speed measurement accuracy

To evaluate the efficiency of the EthoVision estimation of fish swimming speed, the movement of tagged eels was directly measured on the computer screen with a ruler. The position of the eels was measured as the anterior point of the colored spot. Let $\mathrm{S}_{(\mathrm{Z}=z)}$ be the speed measured between $z+1$ consecutive frames (see Fig. 5). Then $z$ is the number of elementary speeds (measured between two consecutive frames, so during a period of $1 / 7.5 \mathrm{~s}$ ) used to measure a

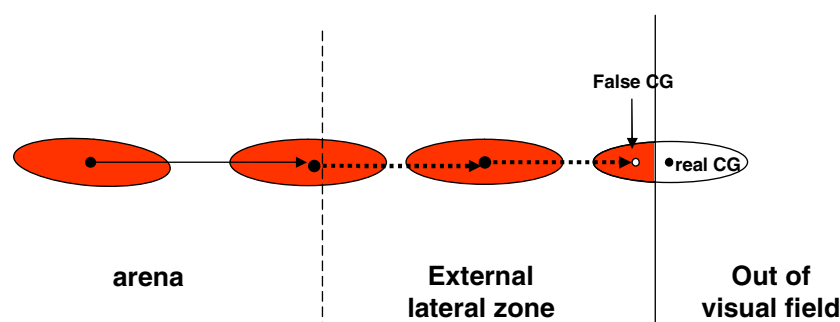

Fig. 4 Representation of the external lateral zone (width $=1 \mathrm{~cm}$ ) of the arena, where the colored spot can be partially out of the visual field. The colored ellipses represent the apparent spot of the tag on the screen. In this area, the positions calculated by the video-tracking software are biased and the covered distance and speed underestimated. For this reason, data from this area were excluded from our analysis $(\mathrm{CG}=$ center of gravity)

mean speed $\mathrm{S}_{(\mathrm{Z}=z)}$. For example, the speed $\mathrm{S}_{(\mathrm{Z}-5)}$ on five consecutive frames is the mean of the five speeds calculated between each six positions. Eight short sequences (two for each color) were analyzed in order to obtain a sample sufficiently large to characterize the degree of comparative precision of the two methods.

Let $\operatorname{Sm}_{(\mathrm{Z}=z)}$ be the speed measured by the manual method, and let $\operatorname{Scg}_{(\mathrm{Z}=z)}$ be the speed measured by EthoVision. The estimated percentage of error was

$\%$ of error $=\left[\left(\operatorname{Scg}_{(\mathrm{Z}=z)} / \operatorname{Sm}_{(\mathrm{Z}=z)}\right) * 100\right]-100$

Estimation of fish relative speed

In the present study, the $\mathrm{S}$ calculated by EthoVision was considered to be the statistical unit, corresponding to the mean speed of an individual during a passage in a given volume; $\mathrm{Sr}$ corresponded to the $\mathrm{S}$ value corrected by the water velocity in this volume $\left(\mathrm{Sr}=\mathrm{S}-\mathrm{V}_{\mathrm{v}}\right)$. Thus, for a given observed speed $\mathrm{S}$ in a given volume of water, a fish swimming with the current would have a relative speed $\mathrm{Sr}<\mathrm{S}$, while a fish swimming against the current would have an $\mathrm{Sr}>\mathrm{S}$.

The speed measurement did not take into account the third dimension, but errors due to movements in the third dimension were likely limited. Indeed, fish, and especially

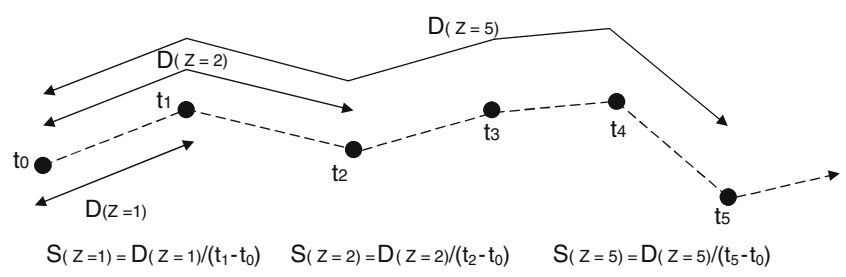

Fig. 5 Measure of speed for different values of $Z(Z=1,2$, or 5). The dashed line is the pathway of the tracked animal. The successive measured positions of the animal as a function of time (every $1 / 7.5 \mathrm{~s}$ ) are represented by the black points. $Z$ is the number of successive elementary speeds used to measure an average speed ( $\mathrm{Sm}$ or $\mathrm{Scg}$ ) 
fish in migration, head for a water current with their motion (negative rheotaxis) or against their motion (positive rheotaxis), which in the present experiment was in the $\mathrm{X}-\mathrm{Y}$ plane.

\section{Results}

\section{Detection of VIE tags}

The four defined areas of detected colors (hue and saturation parameters are given in Fig. 6), corresponding to the four fluorescent colors, were accurately discriminated by the system. These areas presented no overlap, ensuring that the targets would not be confused. The range of saturation of the detected tags was wide because the UV lighting was not homogeneous in the water environment.

The minimal size of detection was fixed at 15 pixels. The size of a detected spot varied between 20 and 300 pixels, depending on the distance and orientation of the live targets
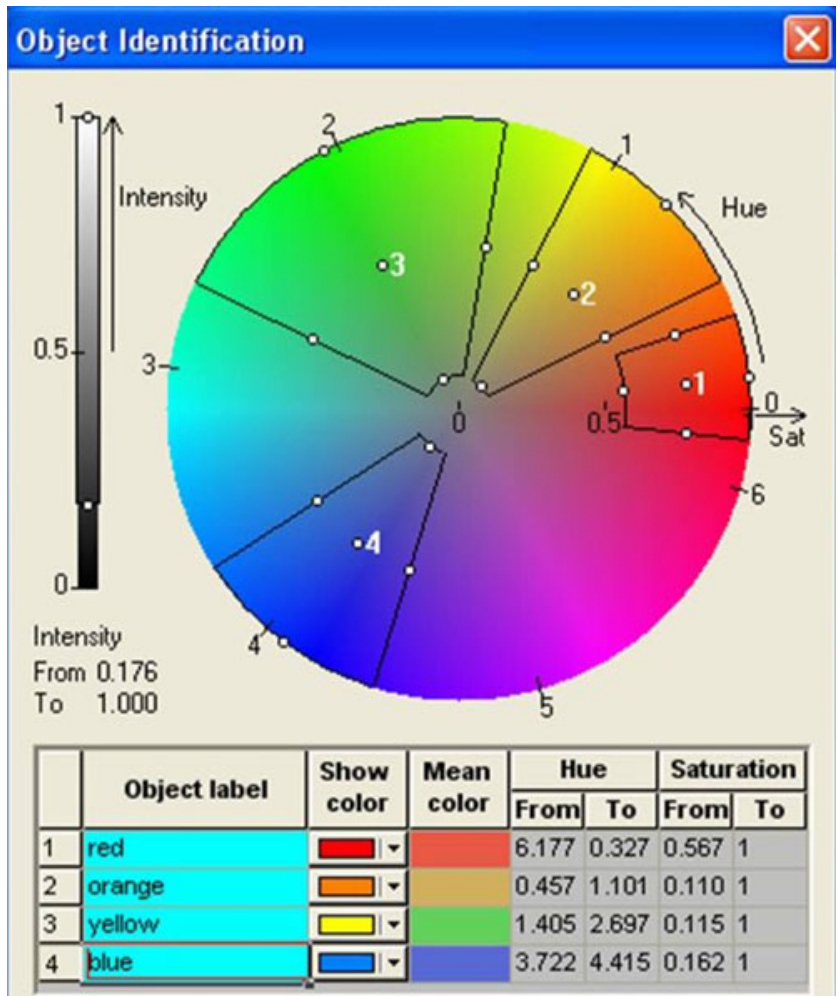

Assign a missing position when an object is not found

\section{OK}

Cancel

Fig. 6 EthoVision window for object identification. Each shape on the disk represents a volume in hue-saturation-intensity (HSI) color space. The horizontal distance from the center represents color saturation, the angle on the disk represents its hue (color), and the vertical distance on the left scale represents its intensity (for more explanation, see Noldus et al., 2001). The four shapes correspond to the fluorescent color of the four tags in our experiment from the camera and the UV. The size of a detected spot also depended on the glass eel speed. At high speed, the spot was larger in the direction of movement (see the blue individual in Fig. 7A), a consequence of the time needed for the camera to capture one image. In this case, color intensity could slightly decrease, but detection was not affected.

Some detection errors were found for the red individual at some locations of the arena, where several external pixels of the red spot were detected as the orange target. However, the editing function in EthoVision (manual deleting of invalid data) allows for the correction of these few errors. In contrast, when the orange individual was present at the same time, the external pixels of the red spot were never detected as an orange target, because the tracking system detects only the larger detected spot (for a range of one given color).
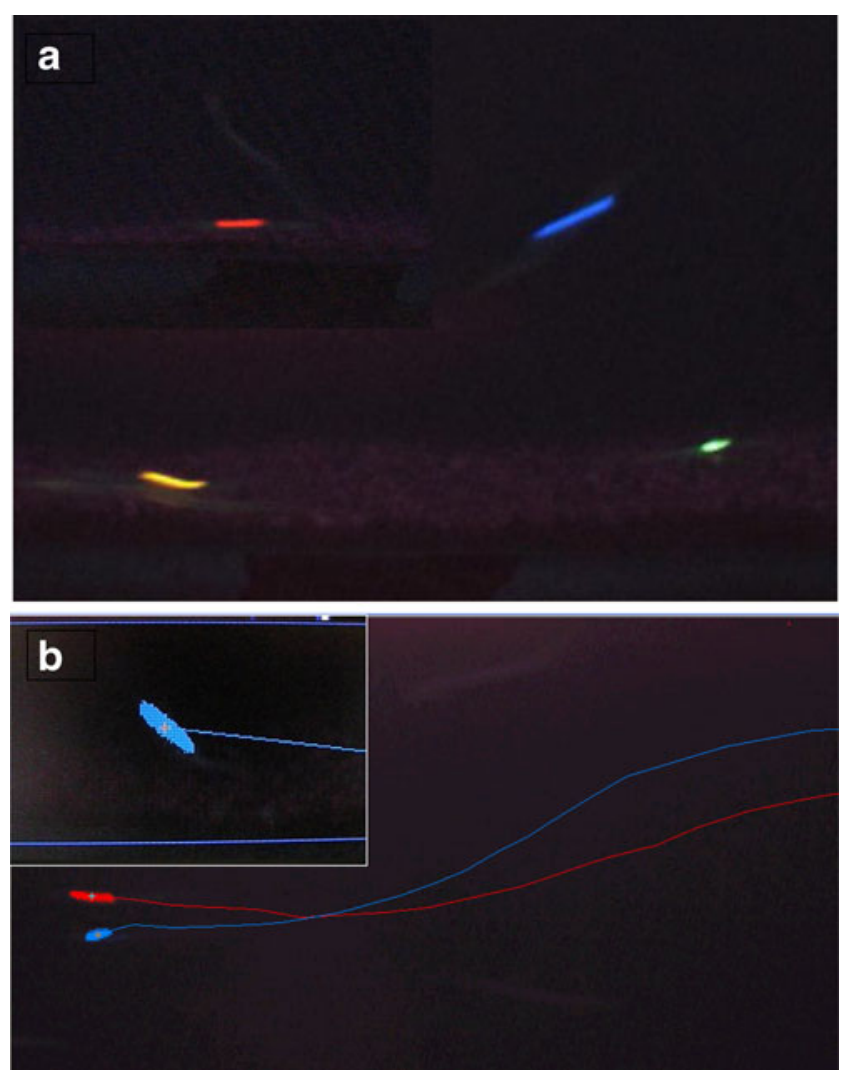

Fig. 7 (A) Image from the front camera illustrating four glass eels marked with fluorescent VIE tags, each VIE tag fluoresced in a specific color. (B) The video-tracking system is able to detect and measure simultaneously the position of each tagged individuals. The large photo shows a part of the arena. The colored spots represented the detected pixels, and the line the previous trajectory during a period of several seconds before. This image illustrates also that identification is not hampered by occlusion (after the trajectories of fish have crossed). The detail photo illustrates the case of the "blue individual"; the white cross represents the center of gravity of the detected spot (blue pixels) and the position of the blue-tagged individual at this instant 
Swimming speed measurement accuracy

The speed value could be different between the manual measurement $(\mathrm{Sm})$, in which the positions are based on the anterior point of the colored spot, and the automatic method (Scg), in which the positions are based on measurement of the center of gravity of the colored spot detected. With the automatic method, the distance covered was underestimated during acceleration and overestimated during deceleration (Fig. 8). However, the underestimating and overestimating were expected to cancel each other out when several successive measurements were made (i.e., when $\mathrm{Z}$ increased), as shown in Figs. 9 and 10. EthoVision also made random errors on shorter paths and/or at lower speed.

For each $\mathrm{Z}$ value, the linear relation between $\mathrm{Sm}$ and $\mathrm{Scg}$ was highly significant $(p<.0001)$. The degree of prediction of Sm by Scg is better when $z$ increases. Figure 9 shows that when $Z \geq 4$, Scg provides a good prediction of $\mathrm{Sm}$ and that prediction accuracy reaches a plateau. Since $Z=4$ represents a duration of $0.52 \mathrm{~s}(4 \times 1 / 7.5)$, a mean speed automatically measured over more than $0.5 \mathrm{~s}$ can be considered a very good estimation.

When $\mathrm{Z}=1$, the error between $\mathrm{Sm}$ and Scg is high, and the method is not relevant for this time duration (1/ $7.5 \mathrm{~s}$ ), especially at a low speed (see Fig. 10). When
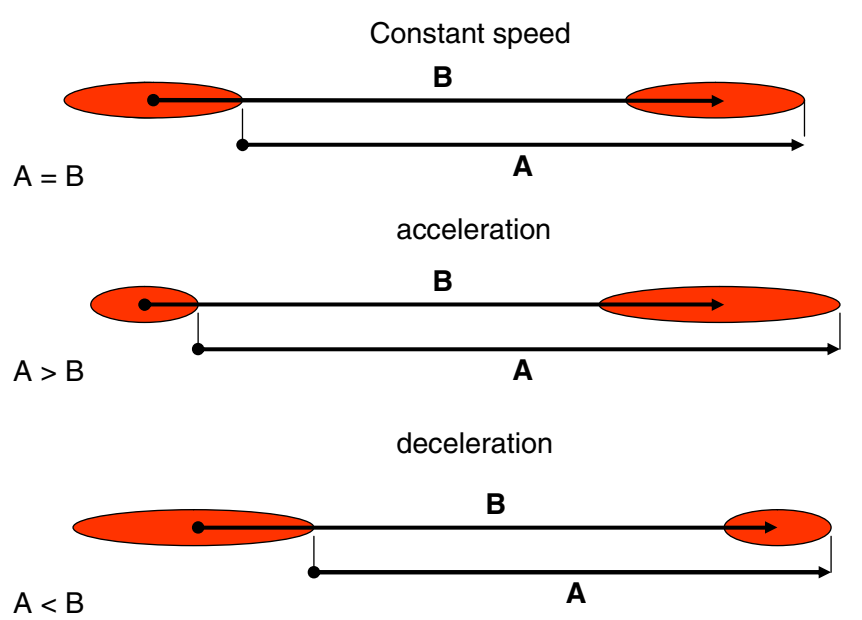

Fig. 8 Diagram illustrating the expected difference in a speed measurement between the manual and automatic methods. In the manual method, the position of the animal is the anterior point of the colored spot. In the automatic method, the position of the animal is the center of gravity of the detected spot. A and B are the distances covered by the eel during a short given time (1/7.5 $\mathrm{s}$, for example), measured manually and automatically, respectively. When the speed is constant, no difference between A and B is expected. During acceleration, the automatic method underestimates the distance covered, and so speed. When this animal decelerates, the automatic measures overestimate the speed

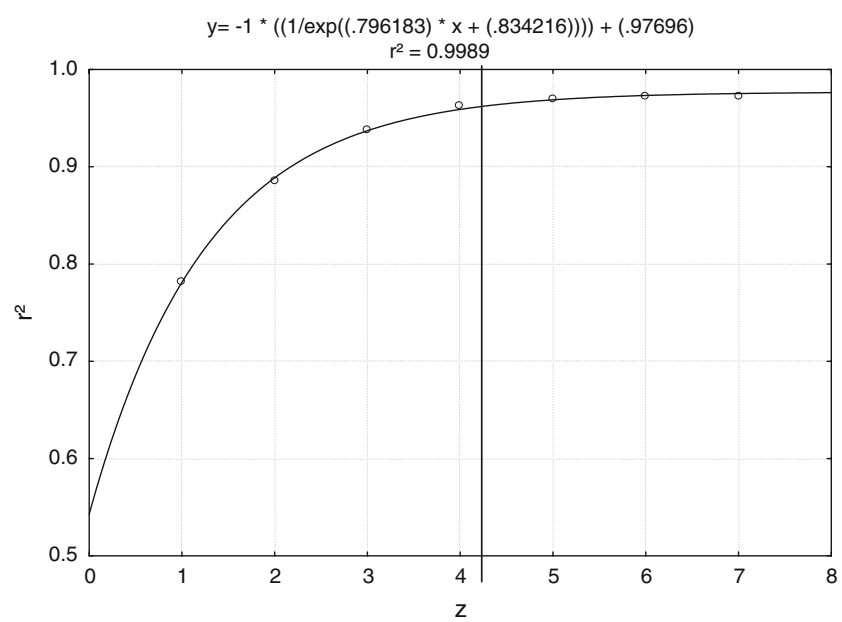

Fig. 9 Values of $r^{2}$ based on the linear regression between Sm and Scg for different values of $Z$. The vertical line represents $0.5 \mathrm{~s}$ on the $x$-axis

$\mathrm{Z}=5$, most error percentages are within $5 \%$ except at a low speed, likely because of the lower accuracy of the measurement at lower speeds (a consequence of the shorter distances in pixels). If we consider data values smaller than $8 \mathrm{~cm} \mathrm{~s}^{-1}$, where the prediction accuracy is worse than in the higher-speed data, the prediction is still greater than $95 \%$ accurate when $Z \geq 10$.

Application to our data

The time spent by fish in a given volume $\mathrm{v}$ largely exceeded $0.5 \mathrm{~s}$. In fact, in each volume, $\mathrm{Z}=27.44 \pm$ 18.48 frames on average, so fish stayed $3.65 \pm 2.64 \mathrm{~s}$, on average, within a given volume $(N=339)$. Consequently, the automatic measurement of S can be considered highly relevant to estimated glass eel speed, even for the lower speed. Figure 11 shows an example of the results at a short time scale, where the distribution of frequency of speed was measured for one individual. Figure 11A shows that the swimming speed $\mathrm{S}$ was positive when the glass eel swam with the current (WC) and was negative when it swam against the current (AC). In this case, the distribution of occurrence was bimodal, due to the swimming mode (AC vs. WC), but the eel swam faster in WC mode $\left(13.0 \pm 3.1 \mathrm{~cm} \mathrm{~s}^{-1}\right)$ than in AC mode $\left(6.4 \pm 2.7 \mathrm{~cm} \mathrm{~s}^{-1}\right)$. There was no clear preference for swimming AC or WC. There were fewer observations of $\mathrm{S}$ close to 0 , in which case the eel would be maintaining a constant position during a short time. Figure 11B shows that the distribution of occurrences of the relative speed $\mathrm{Sr}$ was also bimodal. The values $\mathrm{Sr}>0$ indicate that the fish swam in WC mode and faster than the current (active swimming). When $\mathrm{Sr}=0$, the eel swam in WC mode at the same speed as the water velocity (passive swimming). This behavior 
Fig. 10 Percentage of errors made on Sm, with $\mathrm{Scg}$ as a function of Sm and $z=1$ and 5 . $n$ is the number of observations for each speed class. For $z=5$, no observation is made under $\mathrm{Sm}=2 \mathrm{~cm} \mathrm{~s}^{-1}$
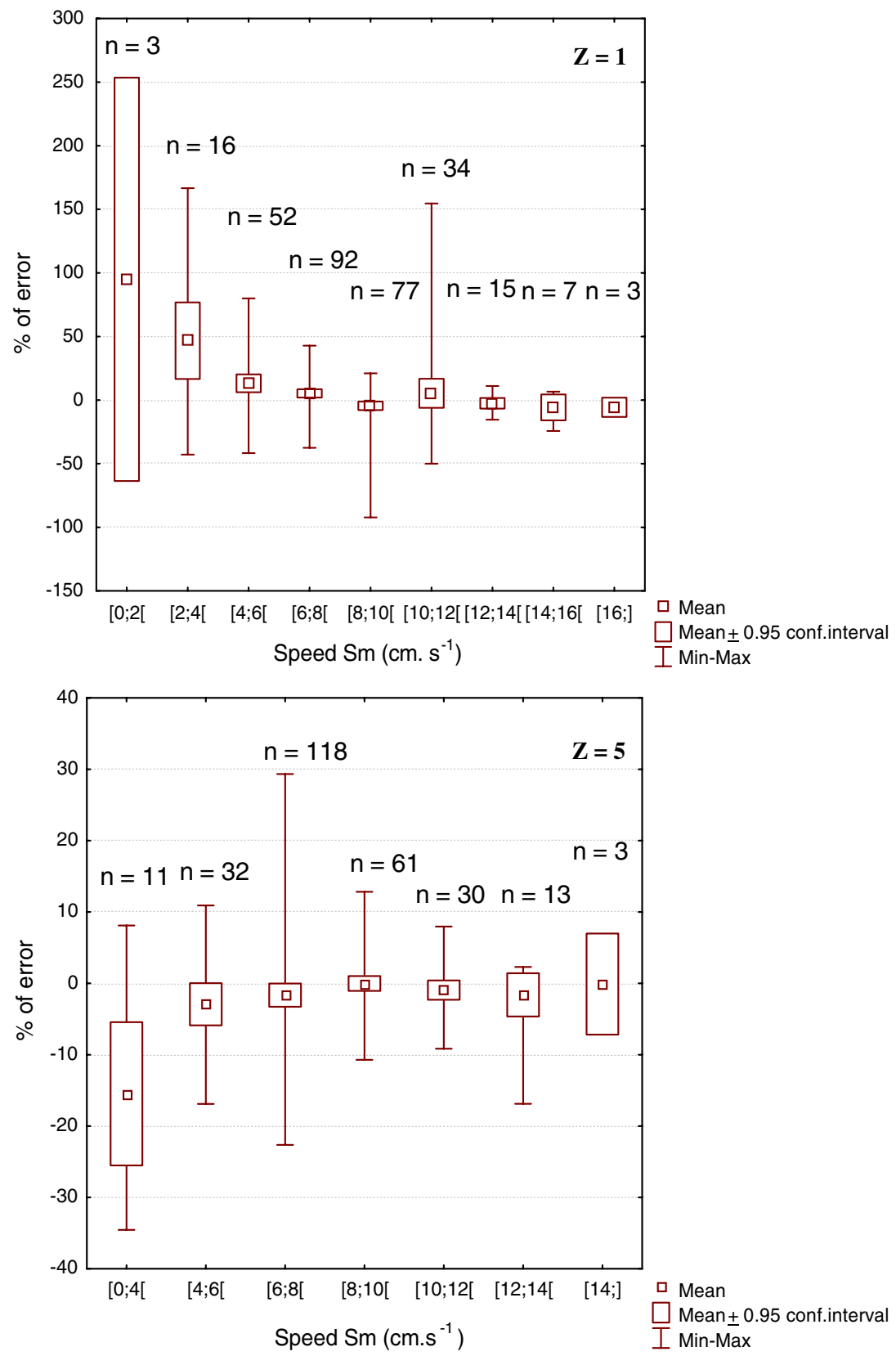

probably saves energy, but glass eels rarely adopt a relative speed close to 0 . In $\mathrm{AC}$ swimming, the relative speed values were higher than in $\mathrm{WC}$ (mean $\mathrm{Sr}=14.1 \pm$ $2.8 \mathrm{~cm} \mathrm{~s}^{-1} ; 4.8 \pm 3.8 \mathrm{~cm} \mathrm{~s}^{-1}$ in WC), which indicates a higher energy expenditure in AC. At the extreme, some $\mathrm{Sr}$ values reached $26 \mathrm{~cm} \mathrm{~s}^{-1}$. The results can also be analyzed at a large time scale for calculation of the distance covered by the same individual over 1 week (Fig. 12). In this example, the distance covered was close to $22 \mathrm{~km}$ for a period of 8 days, with a maximum of $5 \mathrm{~km}$ during one night. The relative distance covered was close to $28.4 \mathrm{~km}$, with a maximum of $7.3 \mathrm{~km}$ in one night.

\section{Discussion}

UV versus IR

Nocturnal observations of animal behavior have used IR light extensively. For example, Zurn, Jang, and Motal (2005) tracked rats in darkness using near-IR light-emitting diodes arranged in strips above the test arena. Dielenberg, Halasz, and Day (2006) tracked rats in a completely dark environment with IR cameras. Patullo et al. (2007) used IR light to observe and detect a crayfish in the dark. However, IR light has a high degree of absorption in water, and 
Fig. 11 Example of results for the short-period analysis: Distribution of frequencies of occurrence for swimming speed $\mathrm{S}$ (panel A) and for relative swimming speed $\mathrm{Sr}$ (panel B), corrected for water current velocity $\mathrm{V}, \mathrm{Sr}=\mathrm{S}-\mathrm{V}$, for one individual eel during a night. For S, negative values correspond to swimming against the current (AC), and positive values to the swimming with the current (WC). For S and Sr, $N=276(n=5,742)$, where $N$ is the number of $\mathrm{S}$ data points (our statistical unit) and $n$ is the total number of elementary speeds to measure the $\mathrm{S}$ values. The statistical unit corresponds to the mean speed calculated during one passage in a given analyzed volume
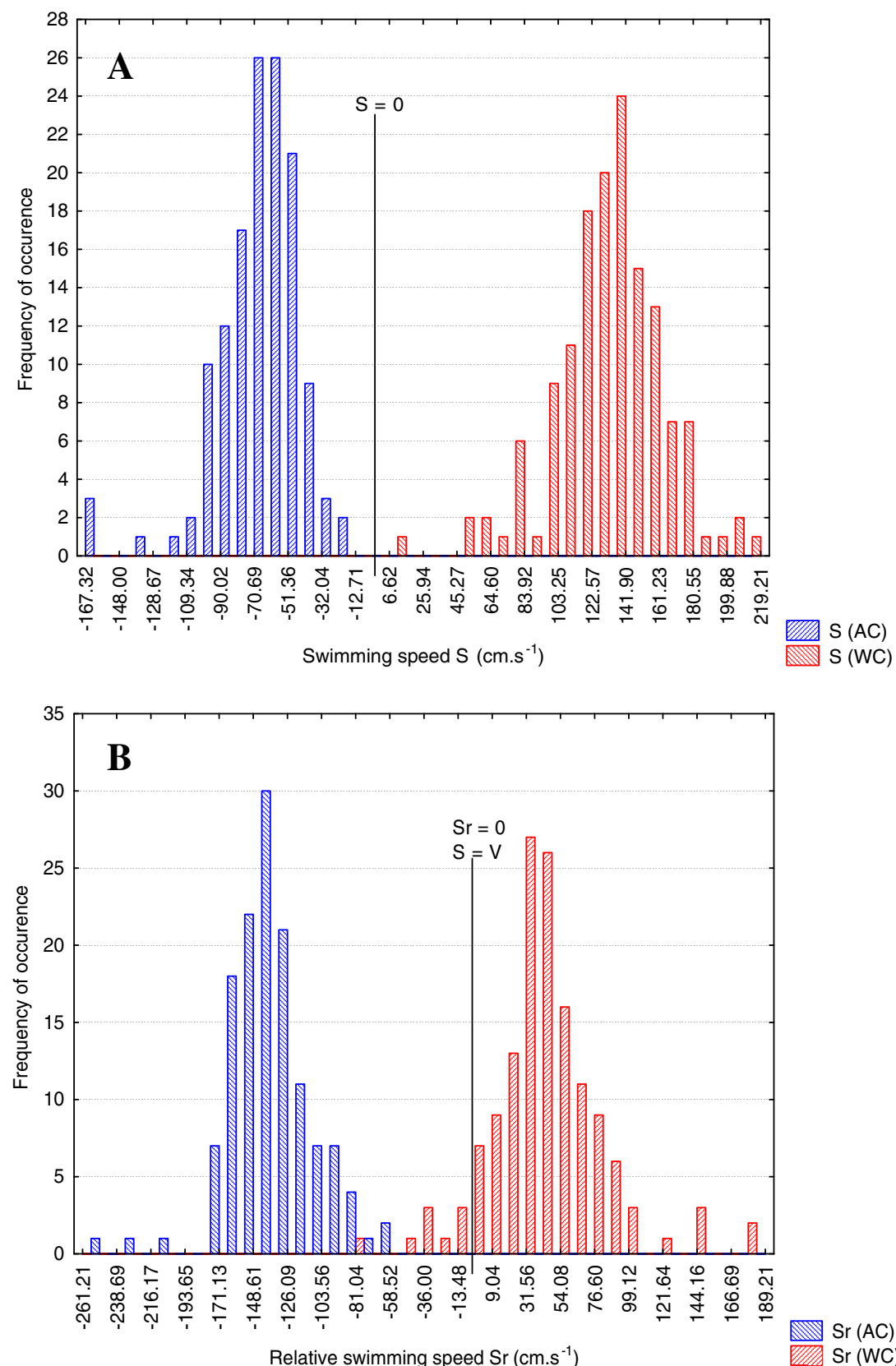

$\operatorname{Sr}(A C)$ $\mathrm{Sr}(\mathrm{WC})$ working with deep water requires powerful IR lamps, which may induce water warming. Contrary to IR light, UV light does not induce a significant change in temperature and can penetrate several meters deep. Although IR light produces good contrast between the tracked object and the background (Bailoo, Bohlen, \& Wahlsten, 2010), it gives only black and white frames, which prevents individual identification by color.

\section{Multitracking}

The detection of fluorescent VIE tags makes it possible to track several individuals. Using VIE tags and EthoVision, four individuals were tracked simultaneously, but this number could probably be increased. On the hue-saturation-intensity (HSI) disk diagram (Fig. 6), the two free areas allow for defining two other HSI volumes to track two other living targets, in the cyan and pink regions. Under our experimental conditions, the pink VIE tags were red under fluorescence and not used. Therefore, if VIE tags were able to fluoresce in cyan or in pink (different wave lengths), it would be possible to track two additional individuals. For a cyan fluorescent mark, no constraint is expected. In contrast, for a pink fluorescent mark, tracking may be compromised, because the pink nuances were largely present in the background of the image due to the UV lighting. 
Fig. 12 Example results for long-period analysis: Distance covered by one individual during a week (by daylight, $\mathrm{D}$, and at night, N). The relative distance corresponds to the distance corrected for the velocity of the water current. Estimations are based on $n=35,819$ measures of speed

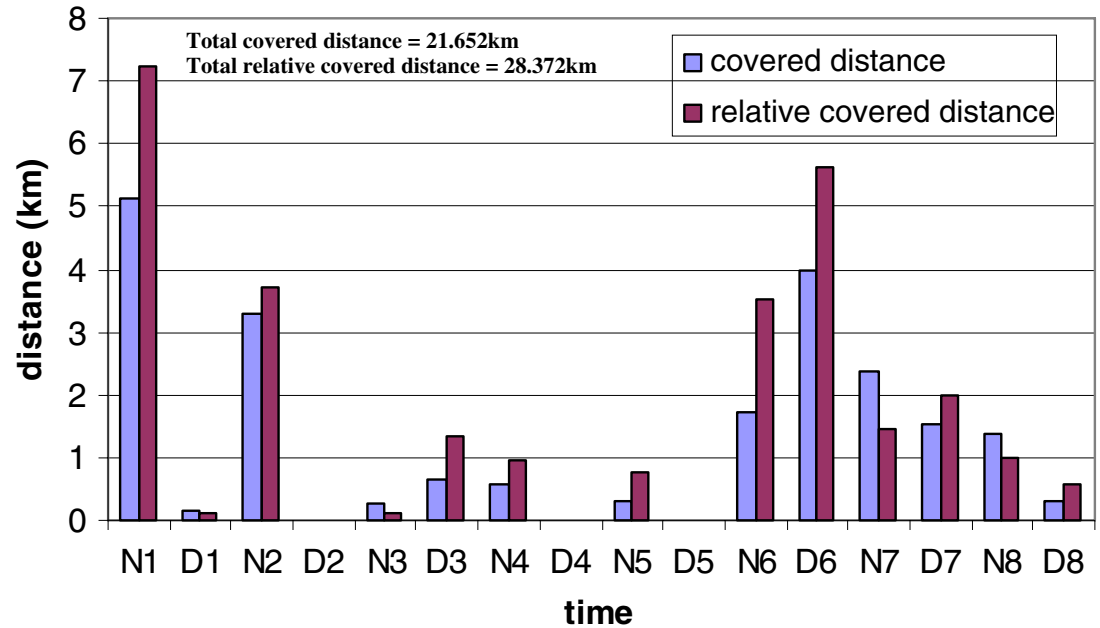

Experiments would be necessary to test whether pinkish noise restricts proper detection of a pink target.

The application of other multitracking systems able to track some individuals with the same color marks (e.g., Feldman \& Balch, 2003) or to distinguish individually animals that are not tagged (e.g., Delcourt, Becco, Ylieff, Vandewalle, \& Poncin, 2009; Egerstedt, Balch, Dellaert, Delmotte, \& Khan, 2005; Kato et al., 2004) could allow for tracking a large number of individuals. However, these systems require continuous tracking of the animal, which must not be lost during the experiment. In this context, the occlusions (contact or superposition of the image of two individuals or more) can generate errors of identification by the loss, inversion, or accumulation of identity (Delcourt et al., 2009). With color tracking, this does not happen. If an individual is lost during a given time, it is identified when it appears again.

Targeted improvements of the color module of EthoVision 3.1 would also be useful for increasing the possible number of tracked fish. Indeed, if EthoVision were able to identify and track an individual on the basis of the combination of several spots with different colors (spaced by a minimum length that would have to be defined according to animal speed and videorecording conditions), this would increase the number of possible targets. The commercial version of EthoVision is not currently able to track a combination of spots. However, Sustr, Spinka, Cloutier, and Newberry (2001), writing complementary algorithms, tracked two pigs, each individual of which was marked by two different-colored marks. In this case, the two marks were used to determine the body axis and to measure the mutual angle of the bodies.

Another way to increase the number of targets would be to take into account color intensity. The range of this third parameter is currently the same for any tracked spot, making it impossible to use this parameter independently for each tracked object. Working with a given intensity scale for a given hue would allow the system to track several objects with pseudocolors, notably during daylight, by taking advantage of white nuances (e.g., white, bluish white, or pinkish white) or black nuances (e.g., anthracite or dark blue), which is not possible in the present HSI system.

For one color, the EthoVision Color-Pro system considers only the largest spot detected (EthoVision manual; Noldus et al., 2001). Tracking several individuals on the basis of spot size is only possible using grayscaling and subtraction detections ${ }^{2}$ (two other detection methods used by the EthoVision system for noncolored movies; Delcourt et al., 2006; Noldus et al., 2001). However, any detection that combines color and size characteristics is difficult if the animal can move in three spatial dimensions, because the size of the spot in the image can vary greatly. In addition, movement speed modifies the size of the imaged spot.

\section{Accuracy of speed measurement and biological results}

By applying fluorescent VIE tags in an aquatic environment and dim light, we have demonstrated that it is possible to track four animals. However, the elongation and contraction of the apparent image of the color spot (the tracked target) when fish accelerate and decelerate may reduce the accuracy of the measurement. Using a higher frame rate would decrease this phenomenon. However, short exposure time would also decrease the quantity of light (emitted by the VIE) that is perceived by the camera.

\footnotetext{
${ }^{2}$ In grayscaling detection, all pixels which have gray values between two threshold values (a dark and a light threshold value) are identified as objects. In subtraction detection, a reference image that contains no objects is compared with the live image containing the tracked animals. All pixels that differ between the two images are identified as objects.
} 
For a given frame rate, if the speed is measured on the basis on several successively detected positions, significantly more precise estimates of speed and distance are obtained. In the present experiment, when all glass eels speeds are taken into account, five successive frames (four successive measures of speed) provided an excellent prediction of speed (less than 5\% error). However, if only low speeds were considered, the precision of the measure would not be as good using only five successive frames. Fortunately, the slower an eel is, the more time the animal spends in a particular volume, so the number of frames $(\mathrm{Z})$ taken into account also increases.

The maximum relative speed observed (near $26 \mathrm{~cm} \mathrm{~s}^{-1}$ ) was close to the $U_{\text {crit }}$ value determined by McCleave (1980) (30 $\mathrm{cm} \mathrm{s}^{-1}$ ), but higher than the $U_{\text {crit }}$ value observed in $A$. rostrata (Wuenschel \& Able, 2008). The measure of the displacement over 8 days shows that a glass eel swimming alternatively with and against the current was able to cover a distance of $21 \mathrm{~km}$ and a relative distance of $27 \mathrm{~km}$ (distance covered if the water current was nil). This value is consistent with the estimated progression of 3-4 $\mathrm{km}^{-1}{ }^{-1}$ (Beaulaton \& Castelnaud, 2005). Bureau du Colombier and colleagues (2009; Bureau du Colombier et al., 2007) demonstrated than the loss of weight in glass eels was related to swimming behavior. However, the measure of activity was only qualitative in that case, with or against the current. The present method will allow a more accurate analysis of weight loss according to swimming behavior (relative speed and level of activity) in the glass eel.

Author Note J.D. and M.Y. contributed equally to this work. J.D. is a postgraduate working for Postdoctoral Researcher at the FRS-FNRS (National Fund for Scientific Research of Belgium). This research was financially supported by a Tournesol Hubert Curien Grant (N20422ZK) and an EGIDE Grant, and by FNRS project Grants $2.4617 .08,2.4569 .06$, and $2.4569 .10 \mathrm{~F}$. The Aquitaine region partly supported the acquisition of the numerical video system (Grant 20051205014A). We are also highly grateful to Jacques Rives for help in settling and monitoring the experiments. We thank E. Huchet, M. Parade, and J.-C. Aymes for their technical assistance.

\section{References}

Aida, K., Tsukamoto, K., \& Yamauchi, K. (Eds.). (2003). Eel biology. Tokyo: Springer.

Aoyama, J. (2009). Life history and evolution of migration in catadromous eels. Aqua-Biosciences Monographs, 2, 1-42. doi: $10.5047 / \mathrm{absm} .2009 .00201 .0001$

Astorga, N., Afonso, J. M., Zamorano, M. J., Montero, D., Oliva, V., Fernandez, H., et al. (2005). Evaluation of visible implant elastomer tags for tagging juvenile gilthead seabream (Sparus auratus L.): Effects on growth, mortality, handling time and tag loss. Aquaculture Research, 36, 733-738. doi:10.1111/j.13652109.2004.01178.x

Bailoo, J. D., Bohlen, M. O., \& Wahlsten, D. (2010). The precision of video and photocell tracking systems and the elimination of tracking errors with infrared backlighting. Journal of Neuroscience Methods, 188, 45-52. doi:10.1016/j.jneumeth.2010.01.035

Bardonnet, A., Bolliet, V., \& Belon, V. (2005). Recruitment abundances estimation: Role of glass eel (Anguilla anguilla L.) response to light. Journal of Experimental Marine Biology and Ecology, 321, 181-190. doi:10.1016/j.jembe.2005.02.004

Beaulaton, L., \& Castelnaud, G. (2005). The efficiency of selective tidal stream transport in glass eels entering the Gironde (France). Bulletin Français de la Pêche et de la Pisciculture, 378-379, 521. doi:10.1051/kmae:2005001

Bolliet, V., \& Labonne, J. (2008). Individual patterns of rhythmic swimming activity in Anguilla anguilla glass eel. Journal of Experimental Marine Biology and Ecology, 362, 125-130. doi:10.1016/j.jembe.2008.06.017

Bolliet, V., Lambert, P., Rives, J., \& Bardonnet, A. (2007). Rhythmic swimming activity in Anguilla anguilla glass eels: Synchronisation to water current reversal under laboratory conditions. Journal of Experimental Marine Biology and Ecology, 344, 54 66. doi:10.1016/j.jembe.2006.12.027

Bonneau, J. L., Thurow, R. F., \& Scarnecchia, D. L. (1995). Capture, marking, and enumeration of juvenile bull trout and cutthroat trout in small, low-conductivity streams. North American Journal of Fisheries Management, 15, 563-568. doi:10.1577/1548-8675

Brennan, N. P., Leber, K. L., \& Blackburn, B. R. (2007). Use of codedwire and visible implant elastomer tags for marine stock enhancement with juvenile red snapper Lutjanus campchanus. Fisheries Research, 83, 90-97. doi:10.1016/j.fishres.2006.08.021

Buchan, A., Sun, L., \& Wagner, R. S. (2005). Using alpha numeric fluorescent tags for individual identification of amphibians. Herpetological Review, 36, 43-44.

Buckley, R. M., West, J. E., \& Doty, D. C. (1994). Internal micro-tag systems for marking juvenile reef fishes. Bulletin of Marine Science, 55, 850-859.

Bureau du Colombier, S., Bolliet, V., \& Bardonnet, A. (2009). Swimming activity and behaviour of European Anguilla anguilla glass eels in response to photoperiod and flow reversal and the role of energy status. Journal of Fish Biology, 74, 2002-2013. doi:10.1111/j.1095-8649.2009.02269.x

Bureau du Colombier, S., Bolliet, V., Lambert, P., \& Bardonnet, A. (2007). Energy and migratory behavior in glass eels (Anguilla anguilla). Physiology \& Behavior, 92, 684-690. doi:10.1016/j. physbeh.2007.05.013

Catalano, M. J., Chipps, S. R., Bouchard, M. A., \& Wahl, D. H. (2001). Evaluation of injectable fluorescent tags for marking centrarchid fishes: Retention rate and vulnerability to predation. North American Journal of Fisheries Management, 21, 911-917. doi: $10.1577 / 1548-8675$

Claverie, T., \& Smith, I. P. (2007). A comparison of the effect of three common tagging methods on the survival of the galatheid Munida rugosa (Fabricius, 1775). Fisheries Research, 86, 285288. doi:10.1016/j.fishres.2007.06.025

Cottrill, P. B., Davies, W. L., Semo, M., Bowmaker, J. K., Hunt, D. M., \& Jeffery, G. (2009). Developmental dynamics of cone photoreceptors in the eel. BMC Developmental Biology, 9, 71.

Davis, J. L. D., Young-Williams, A. C., Hines, A. H., \& Zmora, O. (2004). Comparing two types of internal tags in juvenile blue crabs. Fisheries Research, 67, 265-274. doi:10.1016/j.fish res.2003.11.005

Delcourt, J., Becco, C., Ylieff, M. Y., Caps, H., Vandewalle, N., \& Poncin, P. (2006). Comparing the EthoVision 2.3 system and a new computerized multitracking prototype system to measure the swimming behaviour in fry fish. Behavior Research Methods, 38 , 704-710.

Delcourt, J., Becco, C., Ylieff, M. Y., Vandewalle, N., \& Poncin, P. (2009). A video multitracking system for quantification of individual behavior in a large fish shoal: Advantages and limits. 
Behavior Research Methods, 41, 228-235. doi:10.3758/ BRM.41.1.228

Denoel, M., Bichot, M., Ficetola, G. C., Delcourt, J., Ylieff, M., Kestemont, P., et al. (2010). Cumulative effects of road de-icing salt on amphibian behaviour. Aquatic Toxicology, 99, 275-280. doi:10.1016/j.aquatox.2010.05.007

Dielenberg, R. A., Halasz, P., \& Day, T. A. (2006). A method for tracking rats in a complex and completely dark environment using computerized video analysis. Journal of Neuroscience Methods, 158, 279-286. doi:10.1016/j.jneumeth.2006.05.024

Egerstedt, M., Balch, T., Dellaert, F., Delmotte, F., \& Khan, Z. (2005). What are the ants doing? Vision-based tracking and reconstruction of control programs. Paper presented at the in proceedings of the 2005 IEEE Conference on Robotics and Automation, Barcelona, Spain.

Feldman, A., \& Balch, T. (2003). Automatic identification of bee movement using human trainable models of behaviour Mathematics and Algorithms of Social Insects, December 2003, 14 p.

Frederic, J. L. (1997). Evaluation of fluorescent elastomer injection as a method for marking small fish. Bulletin of Marine Science, 61, 399-408.

Ginneken, V. J. T., \& Maes, G. E. (2005). The European eel (Anguilla anguilla, Linnaeus), its lifecycle, evolution and reproduction: A literature review. Reviews in Fish Biology and Fisheries, 15, 367-398. doi:10.1007/s11160-006-0005-8

Hunt, D. M., Dulai, K. S., Partridge, J. C., Cottrill, P., \& Bowmaker, J. K. (2001). The molecular basis for spectral tuning of rod visual pigments in deep-sea fish. Journal of Experimental Biology 204, $3333-3344$.

Imbert, H., Beaulaton, L., Rigaud, C., \& Elie, P. (2007). Evaluation of visible implant elastomer as a method for tagging small European eels. Journal of Fish Biology, 71, 1546-1554. doi:10.1111/ j.1095-8649.2007.01617.x

Jadot, C., Donnay, A., Ylieff, M. Y., \& Poncin, P. (2005). Impact implantation of a transmitter on Sarpa salpa behaviour: Study with a computerized video tracking system. Journal of Fish Biology, 67, 589-595. doi:10.1111/j.0022-1112.2005.00761.x

Jerry, D. R., Stewart, T., Purvis, I. W., \& Piper, L. R. (2001). Evaluation of visual implant elastomer and alphanumeric internal tags as method to identify juveniles of the freshwater crayfish, Cherax destructor. Aquaculture, 193, 149-154. doi:10.1016/ S0044-8486(00)00477-4

Kato, S., Nakagawa, T., Ohkama, M., Muramoto, K., Oyama, O., Watanabe, A., et al. (2004). A computer image processing system for quantification of zebrafish behaviour. Journal of Neuroscience Methods, 134, 1-7. doi:10.1016/j.jneumeth.2003.09.028

Linnane, A., \& Mercer, J. P. (1998). A comparison of methods for tagging juvenile lobsters (Homarus gammarus L.) reared for stock enhancement. Aquaculture, 193, 149-154. doi:10.1016/ S0044-8486(98)00247-6

Malone, J. C., Forrester, G. E., \& Steele, M. A. (1999). Effects of subcutaneous microtags on the growth, survival, and vulnerability to predation of small reef fishes. Journal of Experimental Marine Biology and Ecology, 237, 243-253. doi:10.1016/S00220981(99)00003-9

McCleave, J. D. (1980). Swimming performance of European eel (Anguilla anguilla (L.)) elvers. Journal of Fish Biology, 16, 445452. doi:10.1111/j.1095-8649.1980.tb03723.x
McCleave, J. D., Brickley, P. J., O’Brien, K. M., Kistner, D. A., Wong, M. W., Gallagher, M., et al. (1998). Do leptocephali of the European eel swim to reach continental waters? Status of the question. Journal of the Marine Biological Association (United Kingdom), 78, 285-306.

Noldus, L. P. J. J., Spink, A. J., \& Tegelenbosch, R. A. J. (2001). A versatile video tracking system for automation of behavioral experiments. Behavior Research Methods, Instruments, \& Computers, 33, 398-414.

Patullo, B. W., Jolley-Rogers, G., \& Macmillan, D. L. (2007). Video tracking in the extreme: Video analysis for nocturnal underwater animal movement. Behavior Research Methods, 39, 783-788.

Peake, T., Matos, R., \& McGregor, P. (2006). Effects of manipulated aggressive "interactions" on bystanding male fighting fish, Betta spendens. Animal Behaviour, 72, 1013-1020. doi:10.1016/j. anbehav.2006.01.029

Purcell, S. W., Blockmans, B. F., \& Nash, W. J. (2006). Efficacy of chemical markers and physical tags for large-scale release of an exploitated holothurian. Journal of Experimental Marine Biology and Ecology, 334, 283-293. doi:10.1016/j.jembe.2006.02.007

Regester, K. J., \& Woosley, L. B. (2005). Marking salamander egg masses with visible fluorescent elastomer: Retention time and effect on embryonic development. American Midland Naturalist, 153, 52-60. doi:10.1674/0003-0031

Schmidt, J. (1922). The breeding places and migration of the eel. Philosophical Transactions of the Royal Society B, 211, 179-211.

Sustr, P., Spinka, M., Cloutier, S., \& Newberry, R. C. (2001). Computer-aided method for calculating animal configurations during social interactions from two-dimensional coordinates of color-marked body parts. Behavior Research Methods, Instruments, \& Computers, 33, 364-370.

Tesch, F.-W. (2003). The eel (3rd ed.). Oxford: Blackwell Science Ltd.

Uglem, I., Noess, H., Farestveit, E., \& Jorstad, K. E. (1996). Tagging of juvenile lobsters (Homarus gammarus (L.)) with visible implant fluorescent elastomer (VIE) tags. Aquaculture Engineering, 15, 499-501. doi:10.1016/S0144-8609(96)01005-9

Woods, C. M. C. \& Martin-Smith, K. M. (2004). Visible implant fluorescent elastomer tagging of the big-bellied seahorse, Hippocampus abdominalis. Fisheries research 66, 363-371

Wuenschel, M. J., \& Able, K. E. (2008). Swimming ability of eels (Anguilla rostrata, Conger oceanicus) at estuarine ingress: Contrasting patterns of cross-shelf transport? Marine Biology, 154, 775-786. doi:10.1007/s00227-008-0970-7

Ylieff, M. Y., \& Poncin, P. (2003). Quantifying spontaneous swimming activity in fish with a computerized color video tracking system, a laboratory device using last imaging techniques. Fish Physiology and Biochemistry, 28, 281-282.

Ylieff, M. Y., Sanchez-Colero, C., Poncin, P., Voss, J., \& Ruwet, J.-C. (2000). Measuring effects of different temperatures on swimming activity and social behavior in groups of Mediterranean marine fish with the EthoVision Color-Pro video tracking system. In proceedings of measuring behavior 2000, 3rd international conference on the methods and techniques in behavioral research (pp. 350-351). Wageningen, The Netherlands: Noldus Information Technology.

Zurn, J. B., Jang, X., \& Motal, Y. (2005). Video-based rodent activity measurement using near-infrared illumination. In Proceedings of the IEEE Instrumentation and Measurement Technology Conference (Vol. 3, pp. 1928-1931). Los Alamitos: IEEE. 